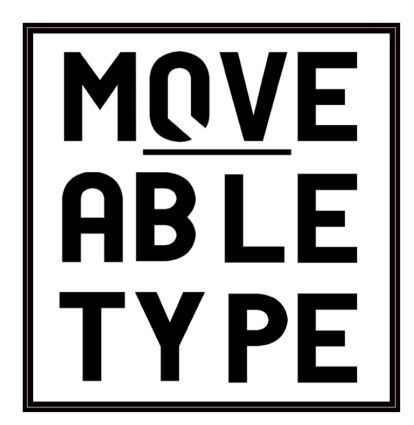

'The Ambitions and Anxieties of Ambience'

Author: Chunlin Men

Source: Moveable Type, Vol.13, 'Ambience' (2021)

DOI: $10.14324 / 111.1755-4527.122$

MoveableType is a Graduate, Peer-Reviewed Journal based in the Department of English at UCL.

(C) 2021 Chunlin Men. This is an Open Access article distributed under the terms of the Creative Commons Attribution License (CC-BY) 4.0https://creativecommons.org/licenses/bv/4.0/, which permits unrestricted use, distribution, and reproduction in any medium, provided the original author and source are credited. 


\title{
The Ambitions and Anxieties of Ambience
}

Chunlin Men

\author{
Ambient Literature: Towards a New Poetics of Situated Writing and \\ Reading Practices. \\ Eds. Tom Abba, Jonathan Dovey and Kate Pullinger. 2021. \\ xii + 377p. £103.99. Palgrave Macmillan.
}

ISBN 978-3-030-41455-9

What do we talk about when we talk about reading and how has this changed in a digital age? Taking an interdisciplinary approach, Ambient Literature: Towards a New Poetics of Situated Writing and Reading Practices (2021) addresses the complications of this question by providing accounts of technologically-assisted and embodied reading experiences that interact with 'the visual, sonic, social and historical resources of places'. ${ }^{1}$ Ambient Literature shifts our attention to the under-researched sensory entanglements between the act of reading, embodiment, city life, and most importantly, their foregrounding and enablement by networking technologies. This collection explores both the creation and consumption of 'ambient literature'. It investigates the contemporary reading experience-which is conditioned by interactions with technology and embedded within location-specific urban data frameworks-as well as the forms of creative writing that transform the sensory and situated dimensions of everyday life into collective meaning-making processes. Ambient Literature responds to the complex embeddedness of this reading and writing with an interdisciplinary collection which integrates expertise from narrative studies, digital media, material studies, and creative writing. The ambition of this project thus locates new research horizons for contemporary literary studies troubled by existential crisis in the digital age. Moreover, it invites us to rethink how reading can be critically shaped by innovations such as 'app design, user experience design, interaction, software authoring, networked content management, localization and GIS (geographical information system)' (2).

It is apparently a difficult project to broaden or redefine some aspects of what we mean by 'reading' within an interdisciplinary vision, as each discipline could possibly demand one book-length study, respectively, to do full justice to their own analytical strengths compatible with ambient literature. This project responds to such difficulty by self-reflexively showcasing the inevitability of incoherence with a strong tone of tentativeness, refusing to pin down a predominant approach or to exhaust the

\footnotetext{
${ }^{1}$ Tom Abba, Jonathan Dovey and Kate Pullinger. Eds. Ambient Literature: Towards a New Poetics of Situated Writing and Reading Practices (London: Palgrave Macmillan, 2021), p.1. Subsequent quotations will appear parenthetically in text.
} 
meaning of ambience. Speaking to 'a cultural potential that is recognisable and real', this project aims to 'test the proposition by commissioning and evaluating new work and to gather these perspectives and findings for wider use and future development' (10). The core thematic concern of this project is the exploration of 'situated writing and reading', a form of place-awareness pointing to a simple reality of reading-we are reading books as living bodies that actively construct individualised and often unpredictable connections to our surroundings and environments. While it has often been observed that the internet can paradoxically hold our attention and distract us, Ambient Literature strives to provide interdisciplinary and literary-critical foundations for studying the situated and embodied dimensions of contemporary acts of reading and how mobile devices and internet technologies can provide new reading experiences that feature some of the intensities of interaction, individualisation and affective contingency.

Although some may suggest ambient literature has long existed, this book presents ambient literature as a new genre of writing which requires abstract theorisation to systematically articulate its potential to reconfigure our understanding of literature. The word 'poetics' in the subtitle indicates the theoretical and philosophical orientations of this project that endeavours to provide concrete, text-based yet abstract, widely applicable formal aesthetics. In Chapter Two, Rita Felski's post critique theory and Bruno Latour's Actor-Network-Theory are appropriated to shed light on 'context' in ambient literary works. This dialogue with critical theories unleashes an explanatory force that illuminates how books like The Cartographer's Confession 'create a third, hybrid context, making London as an urban context go beyond and merge its identities as both the physical space where the reader's ambient reading occurs and as a dynamic narrative setting in the book (55). With a similarly creative connection-building gesture, Chapter Three employs the concept of the palimpsest not only to demonstrate ambient literature's 'alertness to the nature of places and the technologically mediated circulation of information', but also to bring to light its political agencies in affectively reminding the reader of her interdependence with places and in foregrounding the fact that 'the way in which we are entangled, locally, globally and historically, isn't neutral or inert'(97).

This thread of enquiry, integrating aesthetic sensitivity, political consciousness, and ethical consideration, is sustained throughout this ambitious project. Such a methodological multiplicity, which even includes a form of sociologically oriented interview, self-reflexively demonstrates the irreducibility of entanglement within ambient literary works that anticipate the testing of new research techniques and forms of presentation. As the 'Critical Ambience' chapter 
aptly argues, this genre activates the reader's cognitive trajectory of moving back and forth between the 'present moment' and the 'constituting context' (154). This constant performative movement generates an attention-fixing effect that helps the reader stay attuned to 'embodiment, textuality, place, sonics, and technology' (158). These aspects have been excluded by the previous understanding of reading that regards the reader's immersion into books as an immaterial and self-contained act. The chapter on the politics of ambient literature powerfully raises this concern to the level of social otherness, since ambient literature's force in revealing inter-dependence can serve as an effective platform to describe the social experiences based on decolonising 'anti-classist, anti-ableist, anti-patriarchal', and queer political agendas (182).

What transferable implications regarding aesthetics and literary forms can we get from such new critical investment in ambient literature? Put in another way, what are the new strategies, sensitivities, and forms of awareness that attention to situated reading and writing can bring to literary humanities in general? This is a key question that Ambient Literature probably does better in raising than answering, and such an imbalance registers where this project betrays its anxieties-anxieties fueled by a desire to establish the solidity of ambience as a valuable entry point in the humanities. The recent return to literary aesthetics tends to remind us that paranoid reading and the hermeneutics of suspicion have potentially weakened our sensitivity to the cognitive pleasure, emotional attachment and universal sympathy nurtured by reading and literature. Ambient Literature echoes and reinforces such reminding voices. Yet this project seems less articulate and persuasive in probing further the value of ambience as a literary critical term that could be widely applied in analysing other forms of texts, especially those texts less relevant to technological support. Not all fictional texts have the aesthetic-technological space to be accommodated into new media. Neither can the existing technologies do justice to all the formal nuances and stylistic devices used in fictional texts. This incongruity, or mismatch, between technological representation and formal rhetorics/aesthetics, remains a pertinent issue that future projects on ambient literature will need to explore more.

In the chapter 'An Aesthetics of Ambient Literature; Experience, Narrative, Design', Emma Whittaker conducts a case study of The Cartographer's Confession through the lens of John Dewey's aesthetic theory influenced by William James. The major aesthetic categories Whittaker closely examines are structure, rhythm and dynamism, participation, balance and unity. Readers may find these terms very familiar, as basic elements repetitively interrogated by New Criticism, structural and rhetorical narratology, as well as our contemporary interest in affect theory. The 
problem does not lie in the reclamation of these terms but, rather, that this project's renewed interest in them has not truly diversified our tools of talking about new categories of formal tactics and literary aesthetics. Integrating ambient literature into William James's questioning of mind-body dichotomy through redefining emotion could merely confirm the validity of James's argument rather than foreground the unique interpretive value of ambience. To overcome this potential limitation, future projects could be oriented more on addressing questions like: what new categories of readerly pleasure can ambient literature evoke? Is it possible that we talk about ambient literature's aesthetics without resorting to any existing theories? What specific formal devices of ambient literature can be considered relevant to such readerly pleasure? Apart from sociologically-inspired methods like the collection of the participants' subjective narratives, is there space for discussions that explore the inter-connection between ambience and disciplines like psycho-physiological, cognitive, and neurological sciences?

Such anxieties also linger with a palpable intensity in the last chapter, where the authors discuss generative guidelines in terms of how to enact affective experience in the act of creatively writing ambient literature. Repeatedly stressing the complexity and situatedness underlying this form-an inevitable consequence of expressive redundancy in this wide-ranging co-authored project -also indicates the texture of such anxieties. Despite its innovatively graphic manner of presenting a set of design dimensions as a 'valuable mapping', the last chapter could have offered more clues to make solid the rationales for foregrounding the seven categories: embodied reading, temporality, unpredictability, textual space, performance, reflexive technology and movement (310). The sometimes over-concrete thick description of the three texts contributes limited new abstractable rationales of writing ambience literature. The reluctance to elaborate more convincingly on how to measure the abstractness of concepts like 'unpredictability' and 'performance' may slightly undermine this book's ambition to reinvigorate literary studies. 